outstanding argument which can be made against the type of education given in a general degree was not brought into the discussion. This is Dr. C. R. Burch's principle, the broadening effect of specialization-if one studies chemistry, for example, superficially, it is chemistry only; the deeper one studies it, the more one is forced to discover its connexions with other subjects.

In the view of the University of Southampton, expressed by Prof. H. C. Baldry (classics), the general honours degree, under that title, has no future at all. It carries from the past (meaning, for Southampton, the period when it was under the tutelage of London) what according to this view is an indelible association with mediocrity. Southampton, in its regulations governing admissions since 1959, has abolished the general degree, but at the same time has provided a flexibility in the make-up of the course for an honours B.Sc. so that it is possible for it to be essentially similar to one of the less-wide general B.Sc. degrees, such as that provided at Bristol. Prof. G. Geo (Sir Samuel Hall professor of chemistry, University of Manchester), supporting the view that the choice between specialization and a wider curriculum is quite distinct from the need to provide courses at different intellectual levels, advocated a single B.Sc. certificate, with the appropriate class of honours, and the sub. jects studied, and for what periods, separately recorded on the certificate.

Against this view we have the policy, implied by the latest University of London regulations, and made explicit by Prof. J. G. Semple (professor of mathe- matics, King's College), that the general degree serves a dual purpose, being in its honours classes fully equal, and perhaps in the first class a shade superior, to the special degree, but in its pass category offering an easier route to a degree for the less-able student.

This is indeed how it tends to work out in practice, but it is a matter for urgent decision whether this dual purpose use is compatible with a proper recognition of the status of a good general honours degree. Prof. Frank, in his reply, considered that this was only possible if one made a strictly parallel division into general honours, general ordinary, special honours and special ordinary, even though ordinary specialists are the type of graduate which universities are least desirous of producing.

A distinct but important subject was brought into the discussion by Prof. W. F. W. Wynne-Jones (professor of chemistry, King's College, Newcastle on Tyne), namely, the danger that a general honours student may be nobody's baby. He suggested that interdepartmental professors-professors without portfolio-could take responsibility for these students, and Prof. Frank in his reply remarked that such interdepartmental professorships are being increasingly established in the United States, mainly to provide liaison between departments at the researchlevel. It was interesting to see in Prof. Wynne-Jones's proposal the way in which such interdepertmental professors could be given the opportunity to involve themselves with undergraduates.

F. C. Frank

\title{
THE UNIVERSITY GRANTS COMMITTEE
}

\section{ANNUAL REPORT}

$\mathrm{T}$ HE annual returns from universities and colleges in Great Britain in receipt of Treasury grants for the academic year 1958-59, now covering 21 universities and 3 colleges, issued by the University Grants Committee, is this year prefaced by a somewhat longer summary of the Committee's major activities since June 1959*. Much time was given to consideration of possible changes in the university population during the 'sixties and 'seventies ; and, following the Chancellor of the Exchequer's authorization in January 1960 to discuss with the universities the practicability of providing $170,000-175,000$ places by the early 'seventies, the Committee asked the universities to consider what further expansion in student numbers they were prepared to contemplate by that date, together with their requirements for new accommodation. On the basis of subsequent discussions with the universities, the Committee has prepared a report for the Chancellor of the Exchequer. These discussions indicated that the existing universities, including the newly founded University of Sussex, could not of themselves alone provide a sufficient number of places, and that some new institutions were needed. The Committee therefore recommended to the Chancellor in March that immediate steps should be taken to encourage the establishment of new universities at Norwich and

University Grants Committee. Returns from Universities and University Colleges in receipt of Treasury Grant, Academic Year $1958-1959$. Pp. 58. (Cmnd. 1166.) (London : H.M. Stationery Office,
1960 .) 4s. Bd. net.
York, and authority to initiate such foundations was given in April.

After consultation with the Committee of ViceChancellors and Principals, the Committee has advised that these new institutions, which are to be multi-faculty, should have powers from the start to grant both first and advanced degrees, to set their own entrance requirements and to devise their own curricula. It is proposed that the safeguards previously achieved by close association with an existing university institution should be secured for a period by means of an Academic Advisory Committee con. sisting of members from existing universities and, possibly, with lay representatives. Possible means of assisting St. David's College, Lampeter, were explored during the year ; a scheme has since been approved.

An independent sub-committee, with Sir William Hayter as chairman, was appointed to review developments in the universities in the field of Oriental, Slavonic, East European and African studies, consequent on the recommendations of the Scarbrough Commission in 1947, and to consider and advise on proposals for future developments.

An inquiry concluded during the year into the success or failure of students entering universities in October 1955 to study arts, pure science, technology, agriculture or forestry, showed that the proportion who left without success on account of academic failure was only 9.9 per cent, compared with $11 \cdot 3$ per cent in an earlier survey in 1952 . 
The Committee has continued to give thought to ways and means of ensuring the maximum economy in the expenditure of capital funds, and standards of accommodation of various types, based on analyses of comparable buildings, on which universities can base their applications to the Committee for grants for new accommodation, have been suggested. The Committee has also considered and adopted new methods, based on cost analyses, of assessing grants for halls of residence and for science buildings; the new system of assessing grants for science buildings distinguishes between the cost of the building with its basic requirements in the way of heating, lighting and ventilation and its special requirements in the way of services, which may vary greatly.

The number of full-time students in British universities increased further to 100,204 , compared with 95,442 in 1958-59, and statistics collected in October 1959 showed a university population of about 102,000 . There were 6,084 full-time and 2,270 part-time students from overseas within the British Commonwealth, and 4,116 full-time and 1,944 part-time students from foreign countries; for 1957-58 the figures were 6,180 and 2,208 for the Commonwealth, and 3,982 and 1,904 for foreign countries. Of fulltime men students, $36 \cdot 8$ per cent were in arts, $24 \cdot 2$ per cent in pure science, 19.5 per cent in technology, and 12.5 per cent in medicine; these figures compare with $36 \cdot 4,23 \cdot 7,19 \cdot 0$ and $13 \cdot 7$ respectively, in 195758. For full-time women students, the corresponding figures for 1958-59 are $62 \cdot 6,20 \cdot 7,1 \cdot 0$ and $11 \cdot 9$, respectively, and for $1957-58,63.5,20 \cdot 0,0.8$ and $12 \cdot 1$, respectively. Full-time advanced students of pure science numbered 4,071 (34.9 per cent); of technology, 2,125 (18.2 per cent) ; and of medicine, 900 (7.7 per cent) ; 3,185 students were taking postgraduate teacher-training courses.

Of the full-time students, 80,805 were reading for a first degree, 3,928 for a first diploma, and 14,839 were engaged in research or other advanced work; the corresponding figures for 1957-58 were 76,687, 3,937 and 14,069, respectively. Of the new full-time students, $24 \cdot 1$ per cent were in pure science, $16 \cdot 2$ per cent in technology and 8.9 per cent in medicine; in 1957-58 the corresponding figures were $24 \cdot 0,15 \cdot 4$ and $9 \cdot 1$ per cent, respectively.

The proportion of assisted students was 80.5 per cent compared with 79.2 per cent in 1957-58 and 71.9 per cent in 1953-54, ranging from 92.4 per cent in Wales, 87.5 per cent in English universities, excluding Oxford, Cambridge and London, to $70 \cdot 6$ per cent for Scotland. Full-time teaching and research staff increased to 10,823 , compared with 10,542 in 1957-58. The proportion of full-time students residing in colleges or halls of residence was $26 \cdot 6$ per cent, compared with $26 \cdot 4$ per cent in $1957-58 ; 49.6$ per cent were in lodgings and 23.8 per cent at home, but these proportions vary widely between men and women and between institutions.

Of the recurrent income of $£ 52,273,306$ (an increase of $£ 2,855,004$ in $1957-58$ ), $£ 36,448,118$ was from Parliamentary grants $(69 \cdot 7$ per cent), $£ 5,739,316$ (11.0 per cent) from fees, $£ 1,795,344$ from endow. ments, $£ 1,500,918$ from local authority grants, $£ 479,093$ from donations and subscriptions, and $£ 3,657,530$ ( $7 \cdot 0$ per cent) from payments for research. Non-recurrent grants in respect of capital expenditure amounted to $£ 16,554,483$, compared with $£ 11,816,479$ in 1957-58; and of the recurrent expenditure of $£ 51,526,275$ - an increase of $£ 3,191,222$ on $1957-58$ $6 \cdot 8$ per cent was spent on administration, 44.5 per cent on salaries and superannuation of teaching staff, $11 \cdot 0$ per cent on departmental wages, $13 \cdot 2$ per cent on departmental and laboratory maintenance, 3.4 per cent on repairs and maintenance of buildings, and $9 \cdot 7$ per cent on rates, insurance, heating, lighting, etc. Expenditure on libraries, at $\mathfrak{1} 1,979,945$, remained at 3.8 per cent of the total.

\section{WIND TUNNELS AND FLOW VISUALIZATION}

HE Fluid Dynamics Panel of AGARD held
technical sessions at Istanbul, Turkey, during
October 3-4. Fifteen papers were presented, the
two main topics being the 'industrial' use of wind
tunnels, and flow visualization. 'The term 'industrial'
used in this context means 'non-aeronautical'; and
these topics were chosen for this particular meeting
because of the special requirements of the host nation,
which has little aeronautical industry. The meeting
also presented a rare opportunity for workers in a
field of aerodynamics which, while it does not usually
receive the consideration of bodies concerned with
aeronautics, is not afforded much prominence in the
proceedings of the various engineering institutions to
which the work is relevant.
The titles of the ten papers presented on industrial
aerodynamics showed a similarity which was reflected
to a large extent in the contents of the papers.
Nevertheless the papers revealed a very wide diversity
of problems, ranging from work on insect flight (using
live subjects) to that of the aerodynamic oscillations
of long suspension bridges. The introductory paper by Mr. C. Scruton (United Kingdom) gave a brief review of the work carried out at the National Physical Laboratory. This was classified under three main categories: (1) the study of flow problems; (2) the assessment of the steady-wind forces and pressures on vehicles, ships, buildings, etc. ; (3) the oscillatory effects of wind on structures. The techniques used and the conditions for similarity of behaviour between the model and the full scale were briefly indicated. In the first category most of the work was concerned with the flow over the decks of ships, and with pollution from the effluent of industrial chimneys, either with regard to the adjacent buildings or to the surrounding countryside. The oscillatory effects of wind were dealt with at somewhat greater length, with particular mention of the oscillations which can be induced by an air-stream on suspension bridges or tall stacks, and in tube arrays, such as are found in heat exchangers. It is now usual to carry out aerodynamic stability tests in connexion with all major suspension bridge projects, and, for this purpose, it has been shown that costly 